\title{
Information System Efficiency as an Attribute in Environmental Information Systems
}

\author{
Miloš Koch and Zuzana Chvátalová \\ Brno University of Technology, Faculty of Business and Management, \\ Kolejni 4, 61200 Brno, Czech Republic \\ $\{$ koch, chvatalova\}@fbm. vutbr.cz
}

\begin{abstract}
In terms of contemporary civilization development one of the key aspects of environmental protection is the effort to avoid wasting resources. In the case of environmental information systems there is a necessity to strive for such systems, which deliver the highest benefits with the lowest possible consumption of resources (material, energy, as well as human, etc.). Therefore, every information system must be regarded comprehensively, i.e. as a set of mutually interactive subsystems (components, parts). The experiences confirm that the information system, parts of which are not mutually balanced, leads to the lower effectiveness and efficiency of the system as a whole in contrast with a system which may be managed in such a way that all its parts are maintained at a comparable level. Thus, the effectiveness of environmental/information systems must be harmonized as a whole. This paper presents "the HOS method" developed in the Faculty of Business and Management of the Brno University of Technology. This method enables the primary assessment of the balance of organizations' information systems. The HOS analysis is based on a considering of the basic subsystems: Hardware, Orgware and Software (hence the title HOS), but also the following subsystems: Peopleware, Dataware, Customers, Suppliers and Information System Management. The understandable and transparent HOS diagrams for assessing the balance of an information system are presented in a short case study where authors submit also some selected statistics about their current survey results obtained by means of empirical measurement of approximately four hundred chosen organizations from the Czech Republic and Slovak republic. The research is realized using the Zefis portal.
\end{abstract}

Keywords: Balance, Efficiency and Effectiveness, Environment, Environmental Information System, Evaluation, HOS Analysis and HOS Diagram, Information and Communication Technologies, Information system, Subsystems.

\section{$1 \quad$ Introduction}

Information system/s (IS) and information and communication technologies (ICT) are now an indispensable part of the everyday life of people on Earth and environmental information systems are their important subset [5], [6]. Since the early beginnings across centuries up until the substantially accelerated present, the philosophy of calculations, "counting mechanisms", functionality and even the production itself of

J. Hřebíček et al. (Eds.): ISESS 2013, IFIP AICT 413, pp. 31-43, 2013.

(C) IFIP International Federation for Information Processing 2013 
mechanical counting aids, are formed and limited by the needs and possibilities of the real world, of concrete problem-solving (at present, problems of a multiple character), and above all, connected with technical progress. The implementation of IS and ICT in its whole development thus unmistakably corresponds with the challenges posed by material, space, time, cost and energy connected with their environmental aspects, and furthermore, it has been challenged by the users' literacy, the organization and direction, the data accessibility, and by ensuring the safety, and many other factors. With the passing of time, it is necessary to understand this field of human activities as a complex system, i.e., a set of mutually interconnected elements, which reacts by certain behavior to the inputs (i.e., transforms the inputs into outputs) and serves a certain goal. At the same time, there are objective requirements that can be attached to them (e.g. from the viewpoint of the sustainability of development, more in [13]) by the external world.

Assessment of IS has been done from various viewpoints, on different levels of difficulty. It is frequently determined by conditions and according to the purpose which the assessment is supposed to serve. Many authors deal with this [4], [7], [11], [12]. Let us name the following authors of interesting works or projects: R. Weber [14] (the evaluation of theories within the information systems,) R. Gomez and S. Pather [3] (the experiences of ICT evaluation - not only the measurable tangible and quantifiable benefits of ICT but also the intangible benefits of ICT are more important from a developmental perspective). Among Czech experts dealing with IS evaluation let us mention professor J. Voříšek [15].

At the Faculty of Business and Management of the Brno University of Technology, the HOS method is being developed. This method reflects that it is necessary to understand whole IS as a complex of means and activities. This means that the IS is a developed system which is formed by subsystems. The HOS method assesses the level of balance of these subsystems, i.e., the balance of the whole IS (balanced systems are more effective than unbalanced). In dealing with this issue more widely, the concepts of system, its efficiency and effectiveness play a basic part.

At first, the HOS analysis was based on considering three basic subsystems of the IS: Hardware, Orgware and Software (hence the title HOS), and later, these areas were assigned as well: Peopleware, Dataware, Customers, Suppliers, Management IS [8]. The HOS diagrams for assessing the efficiency of a every information system are usefully comprehensible. The scale on the HOS diagram (indicates the level of efficiency of the IS) shows a balance of the IS by using the evaluation of its subsystems, identifying the level of the whole IS and the recommended level for the given IS.

\section{$2 \quad$ Aspects of Information System Efficiency Evaluation}

The basic problem in the HOS method is to determine the subsystems, i.e., which parts of the IS are appropriate for being considered, and how to evaluate their level. Based on a long-term validation of the importance of individual subsystems we can finally select eight basic subsystems (parts, components, areas, elements) of the IS. We consider the eight subsystems presented in Table 1 to be the components of the IS. We evaluate the balance which supports its efficiency. 
Table 1. The subsystems in the HOS method (Source: Authors' elaboration)

The monitored subsystems of the information system using the HOS method

\begin{tabular}{|c|c|c|c|}
\hline Abbreviation & Level & Subsystem & $\begin{array}{l}\text { Description of the evaluation of the } \\
\text { respective subsystem }\end{array}$ \\
\hline HW & $L_{1}$ & Hardware & $\begin{array}{l}\text { Level of the technical equipment (hard- } \\
\text { ware products) of the given organization; }\end{array}$ \\
\hline SW & $L_{2}$ & Software & $\begin{array}{l}\text { Monitoring of features, complexity of } \\
\text { use, operation and controls of the pro- } \\
\text { gram equipment (software products) of } \\
\text { the given organization; }\end{array}$ \\
\hline OW & $L_{3}$ & Orgware & $\begin{array}{l}\text { Rules for the operation of information } \\
\text { systems, the recommended operating } \\
\text { procedures, security rules; }\end{array}$ \\
\hline PW & $L_{4}$ & Peopleware & $\begin{array}{l}\text { Level of computer literacy of users and } \\
\text { primarily their duties and responsibility } \\
\text { with respect to a given information system; }\end{array}$ \\
\hline DW & $L_{5}$ & Dataware & $\begin{array}{l}\text { Availability, management and security } \\
\text { data sets; their usefulness in the organiza- } \\
\text { tion processes; }\end{array}$ \\
\hline $\mathrm{CU}$ & $L_{6}$ & Customers & $\begin{array}{l}\text { The term "customer" can be seen as a } \\
\text { real customer, such as a user of electronic } \\
\text { commerce (e-commerce), citizen looking } \\
\text { for information or as any organization } \\
\text { employee that needs an information sys- } \\
\text { tem and its outputs to work; }\end{array}$ \\
\hline SU & $L_{7}$ & Suppliers & $\begin{array}{l}\text { The term "supplier" is meant in the sense } \\
\text { of } \\
\text { someone who ensures the operation of } \\
\text { the given information system; if it is a } \\
\text { system whose operation and support are } \\
\text { provided by another organization, the } \\
\text { concept of supplier is understood in the } \\
\text { usual sense; if the organization provides } \\
\text { the operations or support of information } \\
\text { systems directly, then the term "con- } \\
\text { tractor" means just these workers; }\end{array}$ \\
\hline MA & $L_{8}$ & Management IS & $\begin{array}{l}\text { The quality of information systems man- } \\
\text { agement in relation to information strat- } \\
\text { egy, the consistency of application of the } \\
\text { rules and the perception of the end-user } \\
\text { information system; }\end{array}$ \\
\hline
\end{tabular}




\section{The HOS Method}

To use the HOS method we can focus on information systems (e.g., environmental information systems).

Let us consider $n \in N$ ( $N$ is a set of natural numbers) and the information system $(I S)$ is composed of individual subsystems $S_{i}, i=1, \ldots, n$ (we can also call them as components, parts, elements, areas, etc.).

The fundamental concept of the HOS method is based on:

- the evaluation of individual subsystem levels $L_{i}, i=1, \ldots, n$ of the information system $I S$, where the level $L_{i}$ is for the subsystem $S_{i}, i=1, \ldots, n$ and

- the identification of the subsystem/s with "the worst" level/s. This/these subsystem/s has/ve a negative impact on (i.e., reduce) the whole $I S$ level $L_{w}$.

Let us imagine that the $I S$ consists of its subsystems and their interrelationships, and it has a defined way of its behavior. If the level of its individual subsystems is different (we understand "level" in terms of the degree to which a considered subsystem conforms to our needs). The question what the level of the $I S$ will be as a whole arises from this debate. The HOS method is primarily designed to find weaknesses in the $I S$, and therefore it is necessary to evaluate the level of the weakest link. This means we assume that the $I S$ is as good as its weakest subsystem, i.e. see (1):

$$
L_{w}=\min \left\{L_{1}, \ldots, L_{m}\right\},
$$

where $L_{w}$ is the level of the whole $I S$,

$L_{i}$ and $L_{j}$ are the levels of subsystems $S_{i}$ and $S_{j}$, $1 \leqq m \leqq n: \quad \forall i, j \in\{1, . ., m\}, i \neq j: L_{i} \neq L_{j}$.

The aim of the HOS method is assessing the level of the key subsystems of the IS and to determine whether the levels of these subsystems are mutually comparable (i.e., they have the same or a similar level). Then we can say that it is a so-called a balanced information system, otherwise we say it is an unbalanced information system, resp. a heavy unbalanced information system. Unbalance of the IS usually leads to the inefficiency of the whole IS, because the system inefficiencies increase, for example, the total cost. Thus, it is obvious that inefficient IS as a whole lead to difficulty in the optimal use of resources, and therefore they burden nature with its excessive utilization and pollution (manufacturing, energy, emissions, waste, biodiversity, etc.).

Let us visualize the situation as an example of the two different compared information systems $I S_{1}, I S_{2}$ with four subsystems $S_{1}, S_{2}, S_{3}, S_{4}$ (see Fig. 1). 


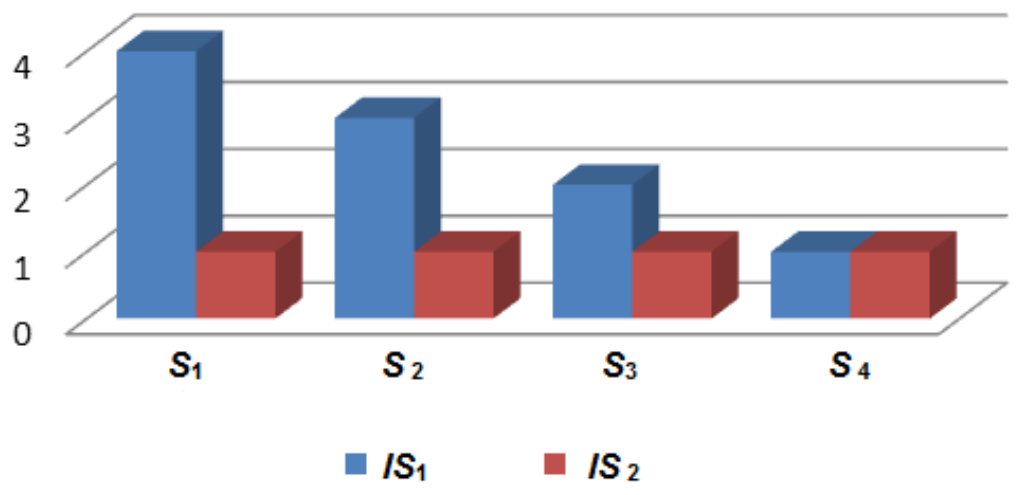

Fig. 1. Subsystem levels of compared $I S_{1}$ and $I S_{2}$ (Source: Authors' elaboration in Microsoft Excel according to [10])

Whole levels of both information systems $I S_{l}, I S_{2}$ are equivalent, i.e., we can write (2):

$$
L_{w_{1}}\left(I S_{1}\right) \cong L_{w_{2}}\left(I S_{2}\right) .
$$

The histogram in Fig. 1 presents this situation: we apply (1) and we can say that (2) holds. In terms of the usefulness of information systems $I S_{I}$ and $I S_{2}$ in the organization we have to say: they are comparable, because the same degree of their whole levels is given as a level of the weakest subsystems of each of them (in both cases, it is the level of the subsystem $S_{4}$ ). However, from the histogram is possible to deduce that the total costs of the information system $I S_{l}$ will be substantially higher than the information system $I S_{2}$, i.e., we can write (3):

$$
T C_{w_{1}}\left(I S_{1}\right)>T C_{w_{2}}\left(I S_{2}\right),
$$

where $T C_{w_{1}}\left(I S_{1}\right), T C_{w_{2}}\left(I S_{2}\right)$ are the total costs of the information systems $I S_{1}, I S_{2}$.

This source of inefficiency in terms of sustainable development definitely cannot be supported. Studies indicate that the improper implementation of IS and ICT leads to the considerable environmental pollution as a result of direct or indirect emissions (mainly $\mathrm{CO}_{2}, \mathrm{SF}_{6}$, etc.), direct and indirect energy consumption, material consumption, water consumption, increase of the amount of (hazardous) waste, etc. It is also necessary to include investment and non-investment costs to protect the environment (recycling, optimization of organization and management, compliance with environmental laws), etc. We believe that the current sustainable development and the respect for the environment are a significant asset and an essential fact to the performance and the success of each organization.

\subsection{The Monitored Subsystems in the HOS Method}

After long-term analyses we selected eight basic subsystems of the IS, see Table 1. 


\subsection{The Subsystem Level}

The first step in evaluating the HOS method is an assessment of the level of individual subsystems, briefly the subsystem level. Each subsystem is rated on a four-point scale as 1 - bad, 2 - rather bad, 3 - rather good, 4 - good.

We even tried a more precise evaluation using the whole range of real interval $<1 ; 4>$. But it turns out that, due to the explanatory character of this method and the way of self-evaluation by the user, a more accurate evaluation is unnecessary ${ }^{1}$.

The assessment of each subsystem can be made by qualified assessment experts (but it excludes the use of methods for the initial assessment by the organization itself), or using control questions for each subsystem by using a questionnaire. The HOS method uses the control issues, ten questions for each subsystem. Their formulation is based on checking the most common weaknesses. For the purpose of the questions we used the expert opinion [1]. Currently, this set of questions is being modified. This modification is based on the feedback evaluation and other concrete experience with surveys in organizations.

The subsystem levels of the IS are plotted as the boundary of the light gray irregular octagon in the sample chart in Fig. 2, Fig. 3 and Fig. 4 (more precisely, the intersection of the octagon boundary and all eight axes).

\subsection{The Whole Level}

The whole level of the IS is determined by its weakest link, see (1). The whole level of the IS is plotted as the boundary of the gray regular octagon in the sample chart in Fig. 2, Fig. 3 and Fig. 4 (more precisely, the intersection of the octagon boundary and all eight axes).

Let $L_{w}$ be the level of the whole information system $I S$ and $L_{i}, i=1, . ., n$ the levels of the subsystems $S_{i}$ of the information system $I S$.

We consider the information system IS a balanced information system provided that all its eight subsystems are at the same level or, at most, three of its subsystem levels are different from the others by no more than one evaluation point ${ }^{2}$, see (4). In this case of we can assume that it is the IS with the optimal efficiency ratio: benefits to costs.

$$
\left[\sum_{i=1}^{n}\left(L_{i}-L_{w}\right) \leq 3\right] \wedge\left[\forall i \in\{1, . ., n\}: L_{i}-L_{w} \leq 1\right]
$$

An unbalanced information system is such IS that does not satisfy the first part of the condition (4), but the each subsystem level (evaluation done on each axis) does not exceed a difference of one evaluation point than has of the whole IS level 's, see (5).

$$
\left[\sum_{i=1}^{n}\left(L_{i}-L_{w}\right)>3\right] \wedge\left[\forall i \in\{1, . ., n\}: L_{i}-L_{w} \leq 1\right]
$$

1 It is possible to access in this way: If someone chooses to assess this using the real number in the range $\langle 1 ; 4\rangle$, the required argument can be rounded down to an integer. We can use the Microsoft Excel command: INT (number).

2 Note: In (4), (5), (6) for $\forall i \in\{1, . ., n\}: \min \left(L_{i}-L_{w}\right)=0$. 
A heavy unbalanced information system is such IS that does not satisfy these conditions (3) and (4) because in the IS the subsystem exists, one which has a level (evaluation on axis) exceeding a difference of one evaluation point compared with what the whole level is (note, that it does not depend on the value of the expression $\sum_{i=1}^{n}\left(L_{i}-L_{w}\right)$, see (6).

$$
\exists i \in\{1, . ., n\}: L_{i}-L_{w}>1
$$

\subsection{The Recommended Level}

The recommended level of IS is based on the importance of the IS which an organization attaches to it. If the IS is indispensable for the organization's activities, then the recommended level is 4, i.e., good. For IS, without, which the activity of the organization is possible, albeit with great difficulties, the recommended level is 3, i.e., rather good. If an organization can exist without the analyzed IS and this state of affairs brings to the organization only very few or no problems at all, the recommended level is 2, i.e., rather bad. In this case, the question arises whether the IS has any sense for the organization at all, and whether the costs incurred are proportional to the benefit. The recommended status must be understood as the minimum required level. The recommended level of the IS is plotted as the bold black curve (the regular octagon) in the sample chart in Fig. 2, Fig. 3 and Fig. 4 (more precisely, the intersection of the octagon boundary and all eight axes).

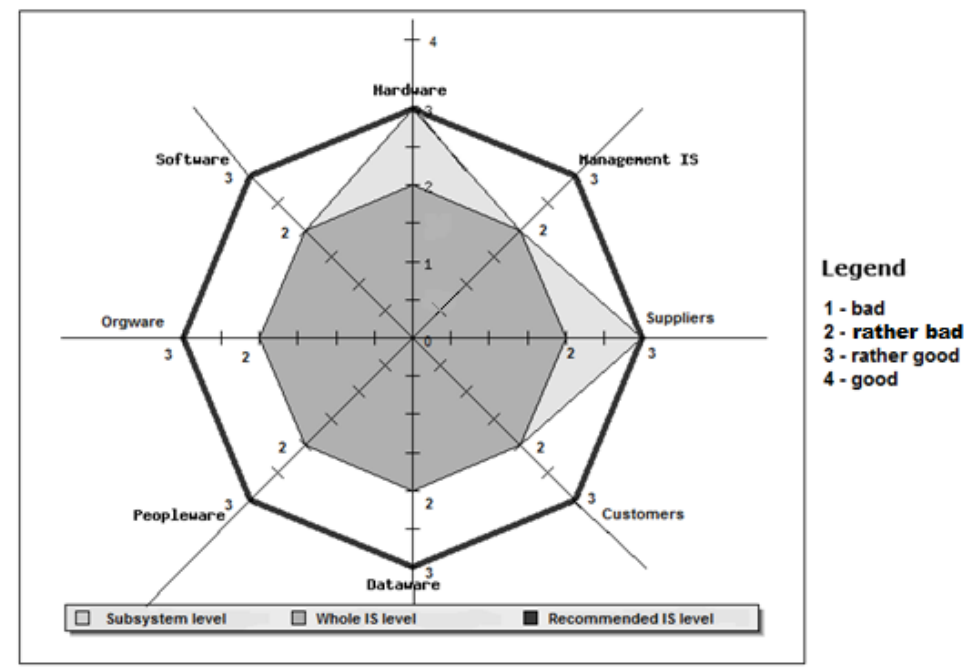

Fig. 2. The HOS diagram for the balanced IS (Source: Authors’ elaboration [10]) 


\section{The HOS Diagram - Case Study}

In the following examples will present the HOS analysis of the IS balance of four organizations from our research using the Zefis portal [10]. We have selected organizations that submit environmental reporting. The results are calculated in the Maple system. Many useful instructions we gain in [2], [8], [9].

\subsection{The Balanced Information System}

In Fig. 2 is presented the sample of the balanced IS's evaluation of one selected organization from the Zefis portal [10]. The HOS analysis of the evaluation of this IS is shown in detail in Tab. 2 and Tab. 3.

Table 2. Subsystem levels of the IS using the HOS method (Source: Authors' elaboration [10])

\begin{tabular}{lcccccccc}
\hline \multicolumn{7}{c}{ SUBSYSTEMS } \\
\hline & HW & SW & OW & PW & DW & CU & SU & MA \\
\hline HOS Diagram Fig. 2 & \multicolumn{7}{c}{ Light grey irregular octagon boundary } \\
\hline Level & $\boldsymbol{L}_{\boldsymbol{1}}$ & $\boldsymbol{L}_{\mathbf{2}}$ & $\boldsymbol{L}_{\mathbf{3}}$ & $\boldsymbol{L}_{\mathbf{4}}$ & $\boldsymbol{L}_{\mathbf{5}}$ & $\boldsymbol{L}_{\mathbf{6}}$ & $\boldsymbol{L}_{\mathbf{7}}$ & $\boldsymbol{L}_{\boldsymbol{8}}$ \\
\hline & 3 & 2 & 2 & 2 & 2 & 2 & 3 & 2 \\
\hline
\end{tabular}

Table 3. The evaluation of the IS using the HOS method (Source: Authors' elaboration [10])

\begin{tabular}{lccc}
\hline & $\begin{array}{c}\text { HOS Diagram } \\
\text { Fig. 2 }\end{array}$ & $\begin{array}{c}\text { According to Condi- } \\
\text { tion/s }\end{array}$ & IS \\
\hline Whole Level & $\begin{array}{c}\text { Grey regular } \\
\text { octagon boundary }\end{array}$ & $\begin{array}{c}(1) \\
L_{w}=\min \{3,2\}=2\end{array}$ & 2 \\
\hline Currrent Status & & $(4)$ & \\
\hline $\begin{array}{c}\text { Recommended } \\
\text { Level }\end{array}$ & $\begin{array}{c}\sum_{i=1}^{8}\left(L_{i}-L_{w}\right)=2 \leq 3 \\
\text { Bold black regular } \\
\text { octagon }\end{array}$ & $\forall i \in\{1, \ldots, 8\}: L_{i}-2 \leq 1$ & Balanced \\
\hline
\end{tabular}

Recapitulation: The monitored IS's whole level is equal to 2. Only two subsystems (HW and SU) are at a level which differs from the whole IS level (namely concerning the admissible 1 point evaluation), thus (4) is fulfilled and therefore the IS is $b a$ lanced. Its recommended level is equal to 3 (rather good).

\subsection{The Unbalanced Information System}

In Fig. 3 we present the sample of the unbalanced IS's evaluation of one organization from the Zefis portal [10]. The HOS analysis of the evaluation of the IS is shown in detail in Tab. 4 and Tab. 5. 


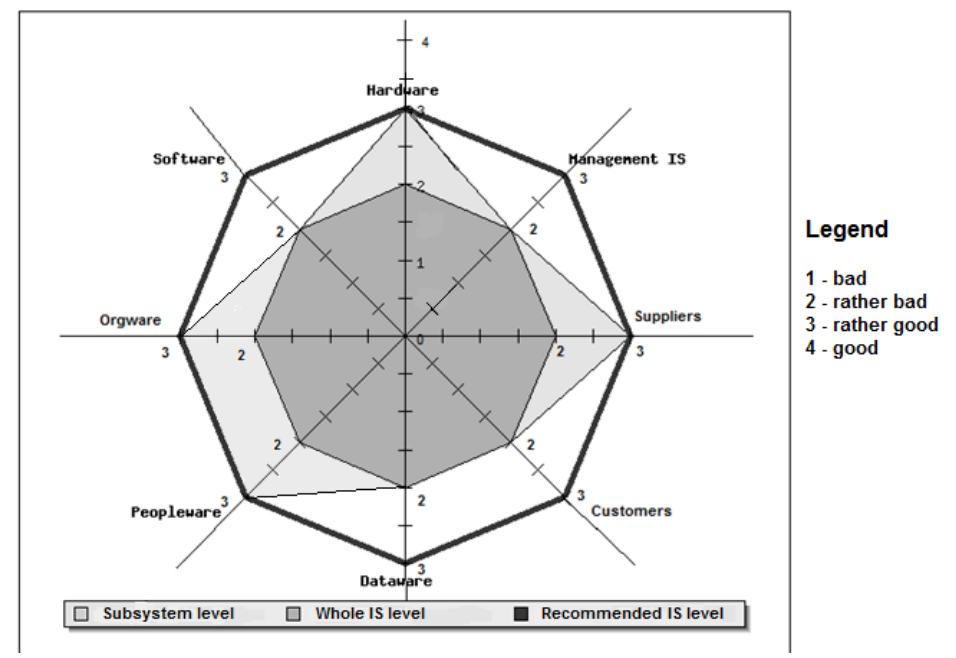

Fig. 3. The HOS diagram for the unbalanced IS (Source: Authors' elaboration [10])

Table 4. Subsystem levels of the IS using the HOS method (Source: Authors' elaboration [10])

\begin{tabular}{lccccccccc}
\hline & \multicolumn{7}{c}{ SUBSYSTEMS } \\
\hline & HW & SW & OW & PW & DW & CU & SU & MA \\
\hline HOS Diagram Fig. 3 & \multicolumn{7}{c}{ Light grey irregular } & octagon boundary \\
\hline Level & $\boldsymbol{L}_{\boldsymbol{1}}$ & $\boldsymbol{L}_{\mathbf{2}}$ & $\boldsymbol{L}_{3}$ & $\boldsymbol{L}_{\mathbf{4}}$ & $\boldsymbol{L}_{\mathbf{5}}$ & $\boldsymbol{L}_{\mathbf{6}}$ & $\boldsymbol{L}_{7}$ & $\boldsymbol{L}_{\mathbf{8}}$ \\
\hline & 3 & 2 & 3 & 3 & 2 & 2 & 3 & 2 \\
\hline
\end{tabular}

Table 5. The evaluation of the IS using the HOS method (Source: Authors' elaboration [10])

\begin{tabular}{|c|c|c|c|}
\hline \multicolumn{4}{|c|}{ INFORMATION SYSTEM } \\
\hline & $\begin{array}{c}\text { HOS Diagram } \\
\text { Fig. } 3 \\
\end{array}$ & $\begin{array}{c}\text { According to Condi- } \\
\text { tion/s }\end{array}$ & IS \\
\hline Whole Level & $\begin{array}{c}\text { Grey regular } \\
\text { octagon boundary }\end{array}$ & $L_{w}=\min \{3,2\}=2$ & 2 \\
\hline Currrent Status & & $\begin{array}{c}(5) \\
\sum_{i=1}^{8}\left(L_{i}-L_{w}\right)=4>3 \\
\forall i \in\{1, . ., 8\}: L_{i}-2 \leq 1\end{array}$ & Unbalanced \\
\hline $\begin{array}{c}\text { Recommended } \\
\text { Level }\end{array}$ & $\begin{array}{c}\text { Bold black regular } \\
\text { octagon }\end{array}$ & -- & $\begin{array}{c}3 \\
\text { Rather } \\
\text { good }\end{array}$ \\
\hline
\end{tabular}

Recapitulation: The monitored IS's whole level is equal to 2. Half of the subsystems ( HW, PW, OW and SU) are at a level which differs from the whole IS level, (namely concerning the admissible 1 point evaluation), i.e. (4) is not partly fulfilled, thus (4) is not valid, (5) is true and therefore the IS is unbalanced. Its recommended level is equal to 3 (rather good). 


\subsection{The Heavy Unbalanced Information System}

In Fig. 4 we present the sample of the heavy unbalanced IS's evaluation of one organization from the Zefis portal [8]. The HOS analysis of the evaluation of the IS is shown in detail in Tab. 6 and Tab. 7.

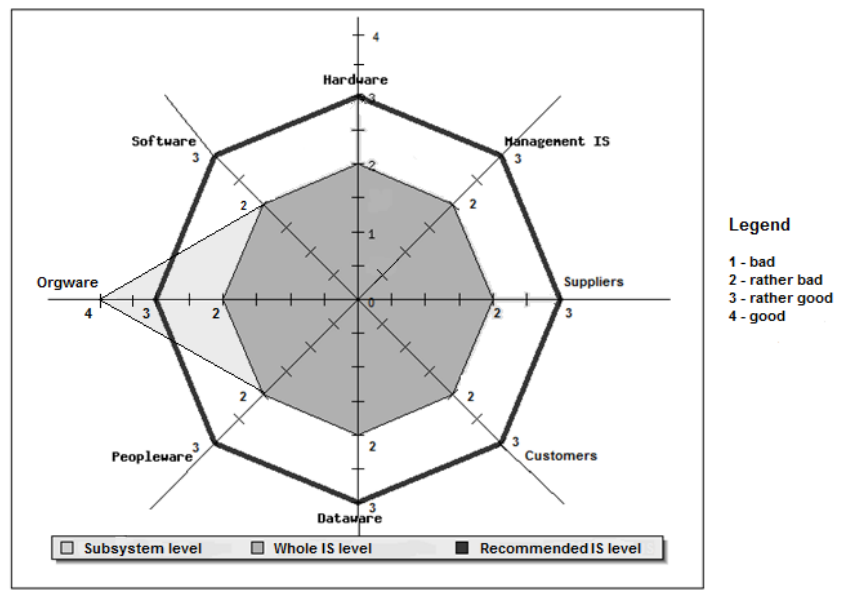

Fig. 4. The HOS diagram for the heavy unbalanced IS (Source: Authors'elaboration [10])

Table 6. Subsystem levels of the IS using the HOS method (Source: Authors'elaboration [10])

\begin{tabular}{|c|c|c|c|c|c|c|c|c|}
\hline & \multicolumn{6}{|c|}{ SUBSYSTEMS } & \multirow[b]{2}{*}{ SU } & \multirow[b]{2}{*}{ MA } \\
\hline & HW & SW & OW & PW & DW & $\mathbf{C U}$ & & \\
\hline HOS Diagram Fig. 4 & \multicolumn{8}{|c|}{ Light grey irregular octagon boundary } \\
\hline Level & $L_{1}$ & $L_{2}$ & $L_{3}$ & $L_{4}$ & $L_{5}$ & $L_{6}$ & $L_{7}$ & $L_{8}$ \\
\hline & 2 & 2 & 4 & 2 & 2 & 2 & 2 & 2 \\
\hline
\end{tabular}

Table 7. The evaluation of the IS using the HOS method (Source: Authors' elaboration [10])

\begin{tabular}{|c|c|c|c|}
\hline \multicolumn{4}{|c|}{ INFORMATION SYSTEM } \\
\hline & $\begin{array}{l}\text { HOS diagram } \\
\text { Fig. } 4\end{array}$ & $\begin{array}{l}\text { According to condi- } \\
\text { tion } / \mathrm{s}\end{array}$ & IS \\
\hline Whole Level & $\begin{array}{c}\text { Grey regular } \\
\text { octagon boundary }\end{array}$ & $L_{w}=\min \{4,2\}=2$ & 2 \\
\hline Currrent Status & & $\begin{array}{c}(6) \\
\sum_{i=1}^{8}\left(L_{i}-2_{w}\right)=2 \leq 3 \\
\exists i=3: L_{3}-2=2>1\end{array}$ & $\begin{array}{l}\text { Heavy unba- } \\
\quad \text { lanced }\end{array}$ \\
\hline $\begin{array}{c}\text { Recommended } \\
\text { Level }\end{array}$ & $\begin{array}{c}\text { Bold black regular } \\
\text { octagon }\end{array}$ & -- & $\begin{array}{c}3 \\
\text { Rather } \\
\text { good }\end{array}$ \\
\hline
\end{tabular}


Recapitulation: The monitored IS's whole level is equal to 2. It is sufficient that the level of one subsystem (OW) differs by more than one evaluation point from the value of the whole IS level; i.e., (4) and (5) are not valid, thus (6) is true and therefore the IS is, heavy unbalanced. Its recommended level is equal to 3 (rather good).

\section{$5 \quad$ The Outcomes and Results}

The Zefis portal [10] offers organizations (free of charge, anonymously) to evaluate the efficiency and balance of their IS using the HOS method (by means of questionnaires).

The HOS method has been tested on a sample of 425 organizations from the Czech Republic and Slovak Republic in the period from 2010 until now (the state of affairs as of March 4, 2013). Fig. 5 presents the aggregated average results of the HOS method. We apply the evaluation criteria (1), (4), (5), (6) then the Fig. 6 represents the sample of monitored organizations with environmental information systems. The Fig. 6 presents the situation in terms of how given organizations understand the importance of their IS, and especially, whether the organizations would function even without the IS.

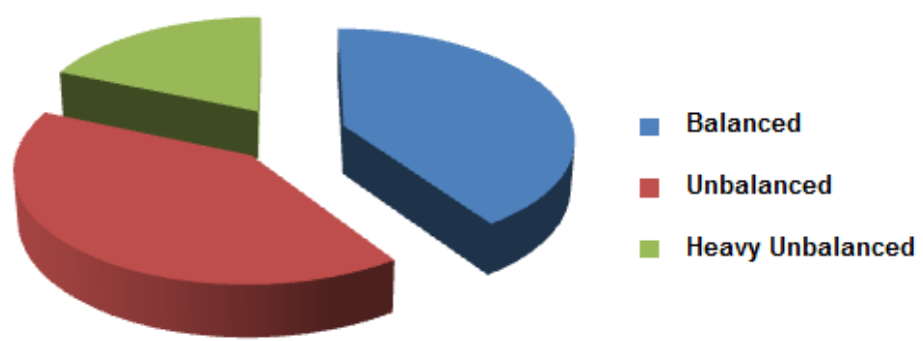

Fig. 5. The proportions of organizations by criteria: a/an balanced / unbalanced / heavy unbalanced state of the monitored IS (Source: Authors' elaboration in Microsoft Excel according to [10])

Let us summarize the results. This output shows that, of the relevant sample of organizations: approximately its two fifths $(40.9 \%)$ have a balanced IS. Approximately the same portion of the sample $(40.5 \%)$ has an unbalanced IS. The rest (18.6\%), i.e., less than approximately one fifth of the sample, has a heavy unbalanced IS. The first two partial results are quite optimistic, because also the part of organizations that has an unbalanced IS has the ability to constructive way to remedy the situation. Organizations with a heavy unbalanced IS probably need to have the costs in addition for the more complicated deciding whether A total renovation of their information systems will be appropriate for them or not. 


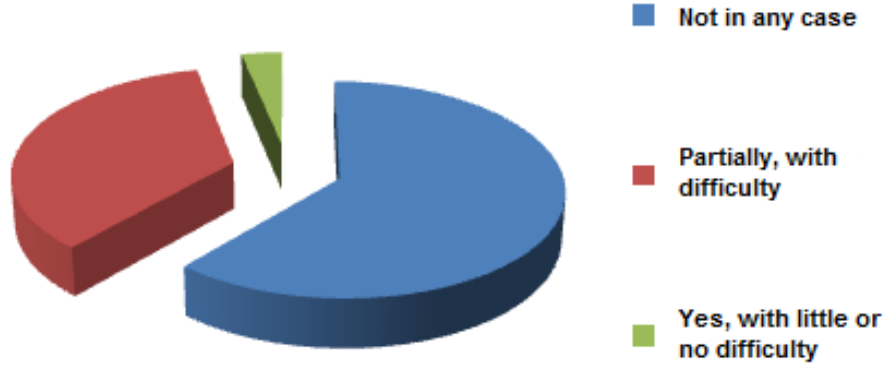

Fig. 6. The proportion of organizations by criteria: the importance of the IS for the organization (Source: Authors' elaboration in Microsoft Excel according to [10])

In our sample survey of meonitored organizations responded, approximately 61.9 $\%$ of the organizations could not function in any case whatsoever without the IS, approximately $34.8 \%$ of them could function only partially, with difficulties, and only approximately $3.3 \%$ of the organizations believe that without this IS they could work with little or no difficulty.

\section{Conclusion}

The HOS method is one of methods implemented at the Zefis portal [10]. This portal is designated mainly for organizations from the Czech and Slovak Republics, for the assessment of their IS including environmental information systems (EIS). (The portal is partly accessible in English as well).

Experience and response organizations using the HOS method and the Zefis portal have brought positive feedback. The base method and guidance of Zefis portal provide an effective tool to perform very rapid initial assessment of the status of their IS including EIS. In turn, leads to a reduction of costs and not only for the organization itself, but also from the perspective of environmental protection. Another important though hidden - attribute is the fact that the HOS method is forcing the organization to the reflection and self-reflection, how to improve a particular subsystems of their IS. This leads to an increase in its overall usefulness and effectiveness for these organizations, as well as for the environment. The HOS method on the Zefis portal shall in addition, when viewing the results of the user suggestions to improve their IS in various subsystems. This can contribute to more effective use of information management systems, which ultimately leads to reduce wasted resources and unnecessary burden for the environment.

Limiting the resource wasting and an unnecessary burdening of the environment is the only possibility of survival of not only of organizations, but also of civilization as such.

Acknowledgments. This paper was supported by grant FP-S-13-2148 'The Application of ICT and Mathematical Methods in Business Management' of the Internal Grant Agency at Brno University of Technology. 


\section{References}

1. Dovrtěl, J.: Selected Aspects of the Effectiveness of Information Systems (Dissertation in Czech). BUT FBM, Brno (2004)

2. Gander, W., Hřebíček, J.: Solving Problems in Scientific Computing Using Maple and Matlab, 4th edn. Springer, Berlin (2004)

3. Gomez, R., Pather, S.: ICT Evaluation: Are We Asking the Right Questions? The Electronic Journal of Information Systems in Developing Countries 50, 1-14 (2012), http: / / www. ejisdc.org/ojs2/index.php/ejisdc/article/view/879

4. Grover, V., Jeong, S.R., Segars, A.H.: Information Systems Effectiveness: The Construct Space and Patters of Application. Information and Management 31, 177-191 (1996)

5. Hilty, L., Page, B., Hřebíček, J.: Environmental Informatics. Environmental Modelling \& Software 21, 1517-1518 (2006)

6. Hřebíček, J., Pillmann, W.: eEnvironment: Reality and Challenges for eEnvironment Implementation in Europe. In: Hřebíček, J., Schimak, G., Denzer, R. (eds.) ISESS 2011. IFIP AICT, vol. 359, pp. 1-14. Springer, Heidelberg (2011)

7. Cha-Jan Chang, J., King, W.: Measuring the Performance of Information Systems: A Functional Scorecard. Journal of Management Information Systems 22, 85-115 (2005)

8. Chvátalová, Z., Hřebíček, J.: Modeling and Simulation Utility Functions with Maple. Mendel Journal Series 1, 552-557 (2012)

9. Chvátalová, Z., Hřebíček, J.: Computational Finance and Finance Economics with Maple. International Journal of Mathematical Models and Methods in Applied Sciences 7, 541-550 (2013)

10. Koch, M.: ZEFIS: Online Assessment for your Information System. BUT FBM, Brno (2013), http: / / www . zefis.cz/

11. Miller, J., Doyle, B.A.: Measuring the Effectiveness of Computer-Based Information Systems in the Financial Services Sector. MIS Quarterly 11, 107-126 (1987)

12. Molnár, Z.: Effectiveness of Information Systems, 1st edn. Grada Publishing, Praha (2000) (in Czech)

13. Soukopová, J., Hřebíček, J., Štencl, M., Trenz, O.: Integration of Economic, Environmental, Social and Corporate Governance Performance and Reporting in Enterprises. Acta Universitatis Agriculturae et Silviculturae Mendelianae Brunensis 59, 157-166 (2011)

14. Weber, R.: Evaluating and Developing Theories in the Information Systems Discipline. Journal of the Association for Information Systems 13 (2012),

http://aisel.aisnet.org/jais/vol13/iss1/2

15. Vořríšek, J.: Strategic Management of Information System and System Integration. Management Press, Praha (2002) (in Czech) 